\title{
Levels of Phytosterol Oxides in Enriched and Nonenriched Spreads: Application of a Thin-Layer Chromatography-Gas Chromatography Methodology
}

\author{
Ana Conchillo, ${ }^{\dagger}$ Luisito Cercaci,,${ }^{\ddagger}$ Diana Ansorena, ${ }^{\dagger}$ \\ Maria Teresa Rodriguez-Estrada, ${ }^{\ddagger}$ GiovanNi LERCKER,,${ }^{\ddagger}$ AND \\ ICIAR ASTIASARÁN*,†
}

\begin{abstract}
Departamento de Bromatología, Tecnología de Alimentos y Toxicología, Facultad de Farmacia, University of Navarra, C/Irunlarrea s/n, E-31080 Pamplona, Spain, and Dipartimento di Scienze degli Alimenti, Università di Bologna, Viale G. Fanin, 40, I-40127 Bologna, Italy
\end{abstract}

\begin{abstract}
The content of phytosterol oxidation products (POPs) in enriched and nonenriched commercial spreads was evaluated by thin-layer chromatography-gas chromatography (TLC-GC). Oxides of $\beta$-sitosterol, campesterol, and stigmasterol were produced by thermo-oxidation (7-hydroxy, 7-keto, and epoxy derivatives) and chemical synthesis (triol derivatives), which were then separated and identified by TLC-GC. Their identification was further confirmed by GC-mass spectrometry (GC-MS). The total amounts of phytosterols found were 6.07 and $0.33 \mathrm{~g} / 100 \mathrm{~g}$ of sample in phytosterol-enriched and nonenriched spread, respectively, whereas the total POPs contents were 45.60 and $13.31 \mathrm{mg} / \mathrm{kg}$ of sample in the enriched and nonenriched products. The main POPs found were the 7-keto derivatives of all phytosterols analyzed; 7-ketositosterol was the most abundant one $(14.96$ and $5.93 \mathrm{mg} / \mathrm{kg}$ of sample in phytosterol-enriched and nonenriched spread). No $\beta$-epoxy and triol derivatives were detected in both types of samples. The enriched spread presented a lower phytosterol oxidation rate $(0.07 \%)$ than the nonenriched one $(0.41 \%)$.
\end{abstract}

KEYWORDS: Phytosterol-enriched spread; phytosterols oxidation products; functional foods

\section{INTRODUCTION}

Over the past few years, phytosterols have become very important from the human health standpoint, since it has been proven that they can reduce serum total and LDL (low-density lipoproteins) cholesterol. In fact, phytosterols decrease dietary and biliary cholesterol absorption in the intestine, increasing fecal excretion of cholesterol.

Plant sterols are not synthesized by animals, but they are obtained from the diet, especially from oils, spreads, cereals, and bakery products. The estimated dietary intake ranges from 250 to $500 \mathrm{mg} /$ day (1). To get a significant reduction (10$15 \%$ ) of serum cholesterol, the intake of phytosterols must be around 2-3 g/day (2). This optimal phytosterols intake corresponds to an approximately 10-fold standard intake of plant sterols from food sources.

The positive biological effects of phytosterols have generated a great interest in elucidating the phytosterol content of many foods, as well as in creating a reliable food composition database that can provide more information about the presence of these compounds in the diet and their effects on health. Furthermore,

* To whom correspondence should be addressed. Tel: 948-425600

Fax: 948-425649. E-mail: iastiasa@unav.es.

University of Navarra.

$\doteqdot$ Università di Bologna. the industry has made a great effort on research and development of phytosterol-enriched foods. According to the Decisions 2004/ 4289 (3), 2004/333 (4), 2004/334 (5), 2004/336 (6), and 2000/ 500 (7) of the European Community, the products that can be enriched with phytosterols, phytostanols, and phytosterol esters are as follows: yellow fat spreads, salad dressings, milk type products, fermented milk type products, yogurt type products, spicy sauces, milk-based fruit drinks, soybean drinks, and cheese type products.

However, no data are available about the oxidative stability of phytosterol-enriched products obtained with different processing technologies and storage conditions. Because of their chemical structure, phytosterols can be oxidized to yield phytosterol oxidation products (POPs), which are structurally similar to cholesterol oxidation products (COPs). Although the negative biological effects of COPs have been extensively documented $(8-10)$, the possible toxic effects of POPs are still unclear and contradictory. In fact, Maguire et al. (11) and Adcox et al. (12) reported that $\beta$-sitosterol oxides exhibit less severe but similar toxicity patterns to those found for COPs. On the other hand, Lea et al. (13) concluded that phytosterols oxides do not exhibit a genotoxic potential and no obvious evidence of subchronic toxicity was detected. Hiroko et al. (14) indicated 
that POPs are absorbed but that they do not promote the development of atherosclerosis in apo E deficient mice.

However, the evaluation of POPs in food is not an easy task, due to the lack of commercial pure standards, as well as to the great number of compounds derived from the different existing phytosterols, showing all of them very similar chemical structures. To overcome this difficulty, several analytical methodologies have been set up for separation and identification of POPs $(15-23)$.

The purpose of this study was to apply a suitable thin-layer chromatography-gas chromatography (TLC-GC) method to establish the extent of oxidation of phytosterols in two types of commercial spreads: conventional and phytosterol-enriched ones.

\section{EXPERIMENTAL SECTION}

Materials and Reagents. Chloroform, $n$-hexane, diethyl ether, methanol, potassium hydroxide, and anhydrous sodium sulfate were purchased from J. T. Baker (Deventer, The Netherlands). Silylating agents (pyridine, hexamethyldisilazane, and trimethylchlorosilane) and large silica TLC plates $(20 \mathrm{~cm} \times 20 \mathrm{~cm} \times 0.25 \mathrm{~mm}$ film thickness $)$ were supplied by Merck (Darmstadt, Germany). Two standards of ( $24 R$ )-ethylcholest-5-en-3 $\beta$-ol ( $\beta$-sitosterol) with different purity percentages were purchased from Fluka (Buchs, Switzerland) [purity: 75\% $\beta$-sitosterol, 13\% (24R)-ethylcholestan-3 $\beta$-ol (sitostanol), and 8\% (24R)methylcholest-5-en-3 $\beta$-ol (campesterol)] and Research Plus (Bayonne, NJ) (purity: 60\% $\beta$-sitosterol and 30\% campesterol). Cholest-5-en$3 \beta, 19$-diol (19-hydroxycholesterol) (purity: 99\%), cholest-5-en-3 $\beta, 7 \alpha$ diol (7 $\alpha$-hydroxycholesterol) (purity: $99 \%$ ), and (24S)-ethylchola-5,22dien-3 $\beta$-ol-7-one (7-ketostigmasterol) (purity: 99\%) were purchased from Steraloids (Newport, RI). (24S)-Ethylcholest-5,22-dien-3 $\beta$-ol (stigmasterol) (purity: 95\%), cholest-5-en-3 $\beta, 7 \beta$-diol (7 $\beta$-hydroxy-

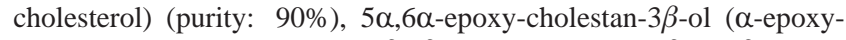
cholesterol) (purity: $87 \%$ ), $5 \beta, 6 \beta$-epoxy-cholestan- $3 \beta$-ol ( $\beta$-epoxycholesterol) (purity: $80 \%$ ), cholestan-3 $\beta, 5 \alpha, 6 \beta$-triol (cholestanetriol) (purity: 99\%), cholest-5-en-3 $\beta$-ol-7-one (7-ketocholesterol) (purity: 99\%), and cholest-5-en-3 $\beta$-ol (cholesterol) (purity: 99\%) were purchased from Sigma (St. Louis, MO). $5 \alpha$-Cholestane (purity: 96\%) was purchased from Fluka. The purity of the standards was controlled by GC. Silica solid phase extraction (SPE) cartridges (Strata SI-1, 500 $\mathrm{mg} / 3 \mathrm{~mL}$ ) from Phenomenex (Torrence, $\mathrm{CA}$ ) were used for sterol oxides purification. 2', $7^{\prime}$-Dichlorofluorescein (sodium salt) was purchased from Carlo Erba (Milan, Italy).

Synthesis of Phytosterol Oxides. Standards of phytosterol oxides are not commercially available, so they were produced using two procedures (thermo-oxidation and chemical synthesis), depending on the type of oxides to be obtained. Eight milliliters of a $\beta$-sitosterol solution $(1 \mathrm{mg} / \mathrm{mL})$ was placed in a $200 \mathrm{~mL}$ open vial, and the solvent was evaporated with nitrogen. Afterward, it was thermo-oxidized by heating at $150{ }^{\circ} \mathrm{C}$ for $2 \mathrm{~h}$ in an oven, to form the $7 \alpha$-hydroxy, $7 \beta$ hydroxy, $\alpha$-epoxy, $\beta$-epoxy, and 7-keto derivatives (mixture A); the resulting thermo-oxidized mixture was dissolved in $8 \mathrm{~mL}$ of $n$-hexane: 2-propanol $(3: 2, \mathrm{v} / \mathrm{v})$. This process was repeated with a solution of stigmasterol and a solution of $\beta$-sitosterol-campesterol, obtaining mixtures $\mathrm{B}$ and $\mathrm{C}$, respectively.

Triol derivatives [ $(24 R)$-ethylcholestan- $3 \beta, 5 \alpha, 6 \beta$-triol (sitostanetriol), (24S)-ethylcholest-22-en-3 $\beta, 5 \alpha, 6 \beta$-triol (stigmastentriol), and (24R)methylcholestan-3 $\beta, 5 \alpha, 6 \beta$-triol (campestanetriol)] were also synthesized in the laboratory, as suggested by Dzeletovic et al. (24). Phytosterol standards were stirred for $2 \mathrm{~h}$ with $m$-chloroperbenzoic acid to form the epoxy derivatives, which were extracted with diethyl ether and purified by SPE. The epoxy derivatives were then refluxed with methanol:6 $\mathrm{M} \mathrm{HCl}(5: 1, \mathrm{v} / \mathrm{v})$ for $2 \mathrm{~h}$, giving rise to the triol derivatives. The latter were extracted with diethyl ether and purified by SPE, thus obtaining solutions D (containing sitostanetriol), E (containing stigmastentriol), and F (containing sitostanetriol and campestanetriol). These three solutions were separately purified by loading $15 \mu \mathrm{L}$ of each one in a $20 \mathrm{~cm} \times 20 \mathrm{~cm}$ TLC plate. A spot of cholestanetriol $(5 \mu \mathrm{L}$ of a $5 \mathrm{mg} / \mathrm{mL}$ ) was also loaded in the same TLC plate as reference for identification of triol derivatives of phytosterols. The mobile phase was a mixture of diethyl ether: $n$-hexane:ethanol (70:30:3, v/v/v). The TLC band of the triol derivatives was visualized by spraying with a $0.2 \%$ ethanolic solution of $2^{\prime}, 7^{\prime}$-dichlorofluorescein sodium salt, under UV light $(254 \mathrm{~nm})$. The band was then scraped off, and extraction of pure triol derivatives from the silica was carried out twice with diethyl ether. The solvent was finally evaporated under nitrogen flow at room temperature, and pure triol derivatives were then dissolved in $n$-hexane2-propanol $(3: 2, \mathrm{v} / \mathrm{v})$.

To separate the $\beta$-sitosterol oxides, about $250 \mu \mathrm{L}$ of mixture $\mathrm{A}$ and $100 \mu \mathrm{L}$ of sitostanetriol were loaded on a $20 \mathrm{~cm} \times 20 \mathrm{~cm}$ TLC plate. A COPs solution was also loaded in the same TLC plate as reference for identification of analogous derivatives of phytosterols. The same procedure was followed for the identification of stigmasterol oxides (mixture B) and $\beta$-sitosterol-campesterol oxides (mixture C). The TLC development conditions were the same as those used for the triol derivatives. Six TLC bands were identified, and their corresponding retention factors $\left(R_{f}\right)$ were calculated. The TLC bands were then separately scraped off, and extraction of sterol oxides from the silica was carried out twice with diethyl ether. The solvent was finally evaporated under nitrogen flow at room temperature.

The different phytosterol oxide fractions, as well as the nonfractionated solutions $\mathrm{A}-\mathrm{F}$, were then subjected to silylation according to Sweeley et al. (25), dissolved in $n$-hexane, and injected into GC and GC-MS for identification.

Determination of Sterols and Phytosterol Oxides in Food Samples. Samples. Commercial samples of traditional vegetable fat spread and low-fat spread enriched with phytosterol esters were purchased in a supermarket. Both spreads contained the following ingredients: water, vegetable oil, buttermilk, and additives (emulsifiers, preservatives, vitamins, flavoring, and color).

Extraction of Sterols and POPs. Lipids were extracted according to a modified version (26) of the method described by Folch et al. (27). Twenty-five milligrams of the Folch extract of the phytosterol-enriched spread and $250 \mathrm{mg}$ of the Folch extract of the nonenriched one were added with $0.025 \mathrm{mg}$ of 19-hydroxycholesterol (internal standard for the quantification of sterol oxides) and $0.5 \mathrm{mg}$ of $5 \alpha$-cholestane (internal standard for the quantification of sterols). Ten milliliters of $1 \mathrm{~N} \mathrm{KOH}$ solution in methanol were then added to perform a cold saponification at room temperature for $18 \mathrm{~h}$, in darkness and under continuous agitation (28). The unsaponifiable material was extracted with diethyl ether.

For the determination of sterols, 1/10 of the unsaponifiable matter was subjected to silylation (25), dried under nitrogen stream, and dissolved in $100 \mu \mathrm{L}$ of $n$-hexane. One microliter of the silylated sterols was injected into GC and GC-MS for quantification and identification purposes, respectively.

Regarding the determination of POPs, the remaining $9 / 10$ of the unsaponifiable matter was purified by silica SPE according to Guardiola et al. (29). POPs were eluted with acetone. The purified fraction was then silylated, dried under nitrogen stream, and dissolved in $100 \mu \mathrm{L}$ of $n$-hexane. One microliter of the silylated sterol oxides was injected into GC and GC-MS for quantification and identification purposes, respectively, and under the same analytical conditions used for the determination of sterols.

GC-Flame Ionization Detector (FID) and GC-MS Conditions. A Fisons Instruments GC 8000 Series model 8160 (Milan, Italy) was equipped with a split-splitless injector and a FID. A fused silica capillary column $(50 \mathrm{~m} \times 0.25 \mathrm{~mm}$ i.d. $\times 0.25 \mu \mathrm{m}$ film thickness $)$ coated with 5\% phenyl-95\% dimethylpolysiloxane (CP-Sil 8CB, ChrompackVarian, Middelburg, The Netherlands) was used. The oven temperature was programmed from 280 (kept for $20 \mathrm{~min}$ ) to $290{ }^{\circ} \mathrm{C}$ at a rate of 0.2 ${ }^{\circ} \mathrm{C} / \mathrm{min}$ and held for $2 \mathrm{~min}$; the oven temperature was then raised to $320{ }^{\circ} \mathrm{C}$ at a rate of $30{ }^{\circ} \mathrm{C} / \mathrm{min}$ and held for $2 \mathrm{~min}$. The injector and detector temperatures were both set at $325^{\circ} \mathrm{C}$. Helium was used as a carrier gas at a flow rate of $2.5 \mathrm{~mL} / \mathrm{min}$; the split ratio was 1:30.

Quantification of sterols was performed by comparing the peak areas of the internal standard ( $5 \alpha$-cholestane) and its concentration with the peak areas of the sample sterols; the same procedure was followed for the quantitation of POPs, using the peak area and concentration of 19hydroxycholesterol (internal standard). The GC response factors of sterols and POPs were considered equal to 1 . The limit of quantitation 


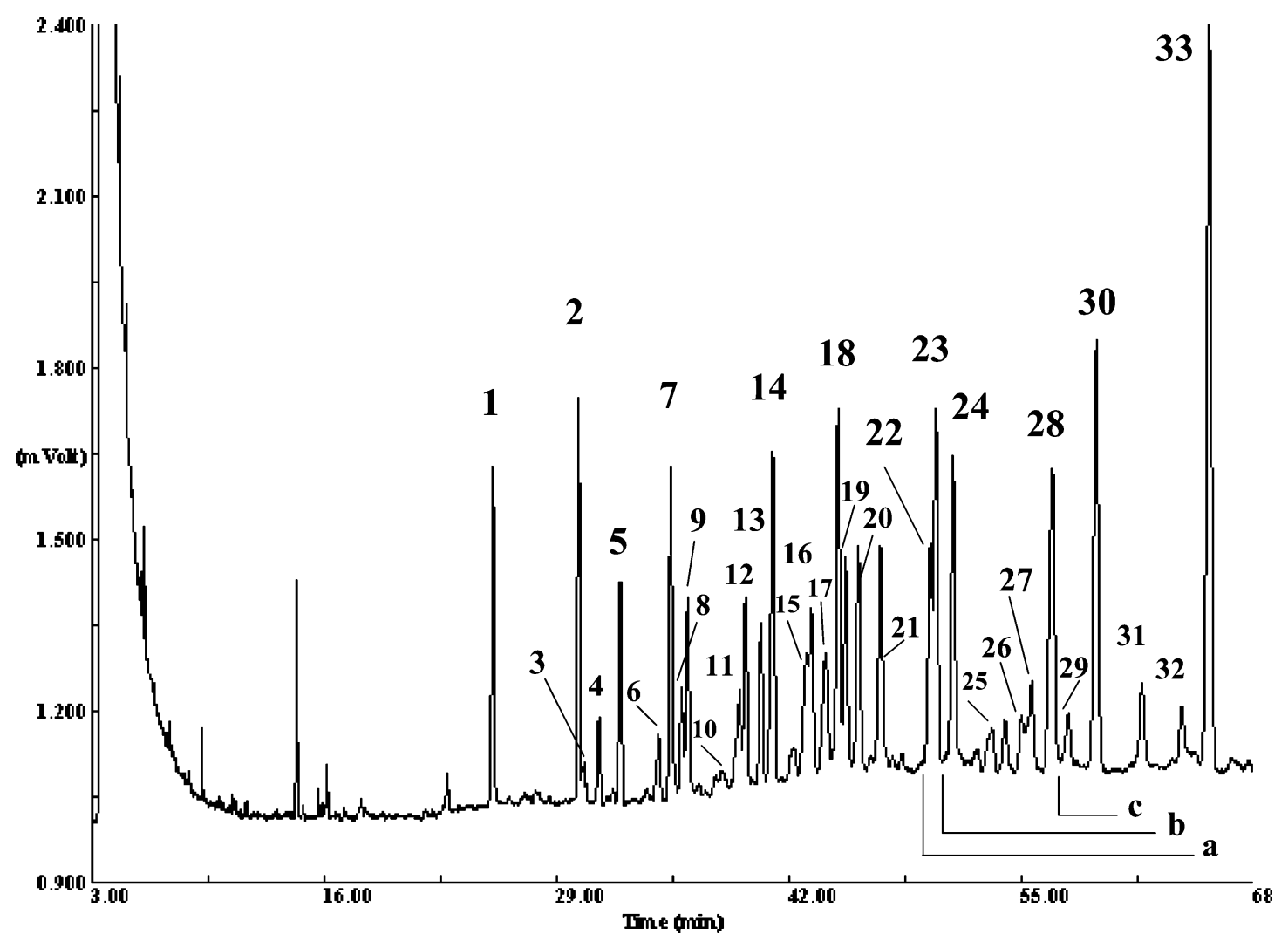

Figure 1. GC trace of a standard mixture of commercially available COPs and synthesized POPs obtained by thermoxidation. Triols are not included in this GC trace, but their retention times (RT) are indicated (a, RT of campestanetriol; b, RT of stigmastentriol; and c, RT of sitostanetriol). For GC conditions, refer to the Experimental Section. Peak identification: 1, 7 $\alpha$-hydroxycholesterol; 2, 19-hydroxycholesterol (internal standard); 3, $7 \alpha$-hydroxycampesterol; $4,7 \alpha$-hydroxystigmasterol; $5,7 \beta$-hydroxycholesterol; $6,7 \alpha$-hydroxysitosterol; $7,5 \beta, 6 \beta$-epoxycholesterol; 8 , unknown; $9,5 \alpha, 6 \alpha$ -

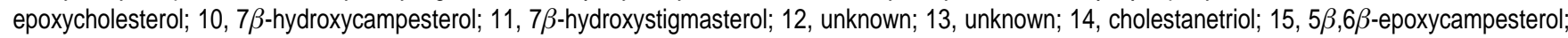
16, side chain-hydroxycampesterol (tentative); $17,5 \alpha, 6 \alpha$-epoxycampesterol; $18,5 \beta, 6 \beta$-epoxystigmasterol $+7 \beta$-hydroxysitosterol; 19 , side chainhydroxystigmasterol (tentative); 20, $5 \alpha, 6 \alpha$-epoxystigmasterol; 21, 7-ketocholesterol; 22, 5 $\beta, 6 \beta$-epoxysitosterol; 23, side chain-hydroxysitosterol (tentative);

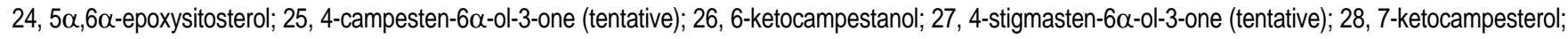
29, 6-ketostigmastenol; 30, 7-ketostigmasterol; 31, 4-sitosten-6 $\alpha$-ol-3-one (tentative); 32, 6-ketositostanol; and 33, 7-ketositosterol.

(LOQ) was $0.25 \mathrm{mg} / \mathrm{kg}$ sample, which was calculated as a signal-tonoise ratio equal to $6: 1$.

Identification of sterols and the synthesized phytosterol oxides were performed by GC-MS. A GC Hewlett-Packard 6890 coupled to a 5973 mass selective detector (Agilent Technologies, CA) was used. The system was fitted with a capillary SPB-5 column $(30 \mathrm{~m} \times 0.25 \mathrm{~mm}$ i.d. $\times 0.25 \mu \mathrm{m}$ film thickness) (Supelco, Bellefonte, PA), and helium was used as the carrier gas $(1 \mathrm{~mL} / \mathrm{min})$. The oven temperature was programmed from 250 to $310^{\circ} \mathrm{C}$ at $0.8^{\circ} \mathrm{C} / \mathrm{min}$. The injector and transfer line temperatures were set at 310 and $280{ }^{\circ} \mathrm{C}$, respectively. Manual injection of $1 \mu \mathrm{L}$ of the solution of standard phytosterol oxides and those obtained from food samples was performed in the split mode at a 1:10 split ratio. The filament emission current was $70 \mathrm{eV}$. A mass range from 40 to $650 \mathrm{~m} / \mathrm{z}$ was scanned at a rate of $1500 \mathrm{amu} / \mathrm{s}$.

Identification of phytosterols was performed by comparing the retention time and mass spectra with those of the purchased phytosterol standards. The mass spectra of POPs were compared with those of the TLC bands of the synthesized compounds, as well as with those reported in the literature (16).

Statistical Analysis. Three lipid extractions were carried out per spread. Each parameter was determined four times in each lipid extract. The data means and corresponding standard deviations are reported in the Tables 6 and 7.

\section{RESULTS AND DISCUSSION}

POPs Synthesis and Identification. The first step of this study was the synthesis of phytosterol oxides, to use them as standards for their identification in the phytosterol-enriched spread samples. The phytosterol oxides formed by thermooxidation in an oven at $150{ }^{\circ} \mathrm{C}$ for $2 \mathrm{~h}$ were as follows: 7-hydroxy derivatives ( $7 \alpha$-hydroxy and $7 \beta$-hydroxy), 7-keto and epoxy derivatives ( $\alpha$-epoxy and $\beta$-epoxy) of $\beta$-sitosterol, campesterol, and stigmasterol. The triol derivatives were prepared using another procedure with $m$-chloroperbenzoic acid, followed by acid hydrolysis.

For the separation and identification of the oxidation products, the POPs mixture of each standard was loaded into a TLC silica plate, together with a spot of a COPs reference solution to be used for the identification of analogous derivatives of phytosterols. Six bands were identified as follows: nonoxidized phytosterols (band $1, R_{f}=0.58$ ), epoxy derivatives (band $2, R_{f}$ $=0.38$ ), 7-keto (band 3, $R_{f}=0.32$ ), 7 $\beta$-hydroxy (band $4, R_{f}=$ 0.25 ), $7 \alpha$-hydroxy (band $5, R_{f}=0.2$ ), and triol derivatives (band $6, R_{f}=0.06$ ). The bands corresponding to $7 \alpha$-hydroxy and $7 \beta$ hydroxy derivatives (bands 5 and 4 , respectively) displayed a blue color after treatment with sulfuric acid, which is in agreement with Chicloye et al. (30), Daly et al. (31), and Bortolomeazzi et al. (32). Injection of these bands in the GCMS showed that 7-ketosterols coeluted in the TLC plate with other compounds, which had a smaller GC peak area and lower GC retention time with respect to those of their corresponding 7-keto derivatives (see Figure 1). These compounds exhibited $\mathrm{m} / \mathrm{z}$ fragments with two more mass units than those of their corresponding 7-keto derivatives; in fact, the trimethylsilyl 
Table 1. Gas Chromatographic RRTs of the Different Phytosterol Oxides, with Respect to 19-Hydroxycholesterol (Internal Standard)a

\begin{tabular}{llccc}
\hline & \multicolumn{4}{c}{ GC RRTs } \\
\cline { 2 - 5 } & \multicolumn{1}{c}{ oxide } & campesterol & stigmasterol & $\beta$-sitosterol \\
\hline TLC band 1 & not oxidized & 1.10 & 1.20 & 1.35 \\
& sterol & & & \\
TLC band 2 & $\alpha$-epoxy & 1.46 & 1.52 & 1.70 \\
TLC band 2 & $\beta$-epoxy & 1.41 & 1.49 & 1.65 \\
TLC band 3 & 7 -keto & 1.89 & 1.96 & 2.18 \\
TLC band 4 & $7 \beta$-hydroxy & 1.26 & 1.30 & 1.50 \\
TLC band 5 & $7 \alpha$-hydroxy & 1.01 & 1.04 & 1.15 \\
TLC band 6 & triol & 1.62 & 1.67 & 1.92
\end{tabular}

${ }^{a}$ For analytical conditions, please refer to the Experimental Section.

(TMS) derivatives of these compounds had characteristic $\mathrm{m} / \mathrm{z}$ 488, 500, and 502 in the 7-ketocampesterol, 7-ketostigmasterol, and 7-ketositosterol TLC bands, respectively. These high $\mathrm{m} / \mathrm{z}$ fragments and the GC retention times could be compatible with the structure of a dihydroxy or a saturated keto derivative of the sterols. However, the first hypothesis was eliminated, because only one [M - 90] mass fragment was found, which is characteristic of the loss of a -OTMS group. In addition, the absence of the [M - 129] and [129] mass fragments further confirmed the lack of an unsaturation in position 5. The mass fragmentation also indicated that these molecules had an hydroxy group in position 3 and a keto group in position 6 . These compounds were, therefore, identified as (24R)-methylcholestan-3 $\beta$-ol-6-one (6-ketocampestanol), (24S)-ethylcholest22 -en-3 $\beta$-ol-6-one (6-ketostigmastenol), and (24R)-ethylcholestan$3 \beta$-ol-6-one (6-ketositostanol) (molecular ions $\mathrm{m} / \mathrm{z}, 488,500$, and 502 , respectively). They could have originated from the corresponding 5,6-epoxide, by opening of the epoxy ring, the formation of the keto derivative in position 6 , and the complete saturation the sterol rings.

In addition, it must be noticed that under these TLC analytical conditions, the two configurational isomers of the epoxy derivatives eluted together in the TLC band 2. Nevertheless, the TLC separation of phytosterol oxides here achieved was more efficient than those reported in other studies. In fact, Apprich and Ulberth (33) used a different mobile phase and were able to obtain only three TLC bands, where 7-hydroxy derivatives were partially separated and 7-ketosterols and epoxysterols eluted together.

Figure 1 shows a GC trace of a standard mixture of COPs and POPs prepared with the available commercial standards and the purified oxides obtained by thermoxidation; triol derivatives are not present in this mixture, but their elution position is indicated in the GC trace. Table 1 reports the GC-FID relative retention times (RRTs) of the different POPs separated by TLC; the RRTs were calculated with respect to 19-hydroxycholesterol, which was used as an internal standard. The elution order of the different classes of oxidation products was identical for every phytosterol: $7 \alpha$-hydroxy, nonoxidized sterol, $7 \beta$-hydroxy, $\beta$-epoxy, $\alpha$-epoxy, triol, and 7-keto derivatives; the series of campesterol derivatives was the first to elute, followed by stigmasterol and $\beta$-sitosterol derivatives. This GC elution pattern of POPs is not exactly the same as those described in other studies $(19,21,23,33,34)$, which may be due to the type and dimensions of the GC column. Nevertheless, it must be noticed that in all cases, the first and last eluting phytosterol oxides were $7 \alpha$-hydroxycampesterol and 7-ketositosterol, respectively. Under the analytical conditions here tested, not all POPs peaks were perfectly resolved; in particular, a poor baseline separation between all $\beta$-epoxy derivatives and some side chain hydroxy
Table 2. Phytosterol Formation Yields by Thermo-oxidationa

\begin{tabular}{|c|c|c|c|c|}
\hline & \multicolumn{4}{|c|}{$\begin{array}{c}\text { phytosterol formation yields } \\
\text { (\% area in thermo-oxidized solutions) }\end{array}$} \\
\hline & \multirow{2}{*}{$\frac{\text { mixture } \mathrm{A}}{\beta \text {-sitosterol }}$} & \multirow{2}{*}{$\frac{\text { mixture B }}{\text { stigmasterol }}$} & \multicolumn{2}{|c|}{ mixture $\mathrm{C}$} \\
\hline & & & $\beta$-sitosterol & $\overline{\text { campesterol }}$ \\
\hline not oxidized & $69.3(5.1)$ & $62.0(6.0)$ & $40.5(2.2)$ & $18.6(1.9)$ \\
\hline $7 \alpha$-hydroxy & $0.8(0.1)$ & $2.0(0.3)$ & $1.7(0.2)$ & $0.3(0.1)$ \\
\hline $7 \beta$-hydroxy & $1.4(0.3)$ & $2.3(0.4)$ & $2.5(0.6)$ & $0.4(0.1)$ \\
\hline$\beta$-ероху & $1.5(0.4)$ & $2.1(0.6)$ & $1.6(0.3)$ & $0.6(0.1)$ \\
\hline$\alpha$-epoxy & $3.5(0.7)$ & $5.5(0.3)$ & $2.4(0.5)$ & $1.4(0.4)$ \\
\hline 7-keto & $9.5(1.8)$ & $18.4(1.1)$ & $15.4(0.7)$ & $6.8(0.2)$ \\
\hline others & $8.0(0.5)$ & $8.7(0.5)$ & $7.2(0.3)$ & \\
\hline
\end{tabular}

${ }^{a}$ For analytical conditions, please refer to the Experimental Section. Values are given as means and standard deviations between parentheses.

Table 3. Mass Spectrometric Data of TMS Derivatives of Sitosterol Oxides

\begin{tabular}{|c|c|c|c|c|c|c|c|}
\hline \multirow{7}{*}{$\begin{array}{l}7 \alpha \text {-hydroxy } \\
7 \beta \text {-hydroxy } \\
\beta \text {-epoxy } \\
\alpha \text {-epoxy } \\
\text { triol } \\
7 \text {-keto }\end{array}$} & \multirow{2}{*}{$\frac{\mathrm{M}+}{574}$} & \multicolumn{6}{|c|}{ major significant ions } \\
\hline & & 559 & 484 & 253 & 129 & & \\
\hline & 574 & 559 & 484 & 233 & 129 & & \\
\hline & 502 & 412 & 394 & 384 & 253 & 129 & \\
\hline & 502 & 412 & 394 & 384 & 253 & 129 & \\
\hline & 592 & 574 & 484 & 431 & 349 & 283 & 129 \\
\hline & 500 & 485 & 410 & 395 & 129 & & \\
\hline
\end{tabular}

derivatives (discussed latter on) was found. Scarce separation between campestanetriol and $\beta$-epoxysitosterol was also observed. Large amounts of stigmastentriol and sitostanetriol could also give some partial overlapping problems with $\alpha$-epoxysitosterol and 6-ketostigmastenol, respectively. Johnsson and Dutta (34) have recently improved POPs separation and enhanced baseline resolution by combining two capillary columns of different polarity (midpolar and a nonpolar columns). Besides the partial overlappings, there are a series of peaks that have not been definitively identified. In fact, peaks 25,27 , and 31 of Figure 1 have been tentatively identified as 4-campesten-6-ol3-one, 4-stigmasten-6-ol-3-one, and 4-sitosten-6-ol-3-one, respectively; the identification was performed by studying the mass fragmentation pattern and by comparing it with those reported by Johnsson and Dutta (34). Peaks 16, 19, and 23 display a typical mass fragmentation of a side chain hydroxy derivative. More studies are being carried out in order to completely elucidate the chemical structure of these peaks.

Table 2 reports the yields of phytosterol formation by thermooxidation (expressed as \% of area in thermo-oxidized solutions), which are higher than those obtained in previous studies; in fact, Apprich and Ulberth (21) had POPs yields ranging from 0.35 to $0.65 \%$. The high efficiency of POPs production by thermo-oxidation allowed us to obtain enough amounts for POPs identification and separation by GC and GC-MS.

To confirm the identification of POPs, GC-MS of the TLC bands was performed. The COPs mass spectra, as well as POPs spectra reported in the literature $(16,32,35)$, were used to support identification of POPs. Major significant ions used to confirm identification of TMS derivatives of oxidation compounds of $\beta$-sitosterol, campesterol, and stigmasterol are shown in Tables 3-5. The oxidized products of campesterol, stigmasterol, and $\beta$-sitosterol presented ions that increased in 14,26 , and $28 \mathrm{amu}$, respectively, with regard to the molecular weight of COPs; this correlates to the chemical structure of the side chain of phytosterols. The identification of the 7-hydroxy, epoxy, triol, and 7-keto derivatives of the campesterol, stigmasterol, 
Table 4. Mass Spectrometric Data of TMS Derivatives of Stigmasterol Oxides

\begin{tabular}{lllllll}
\hline & M+ & \multicolumn{5}{c}{ major significant ions } \\
\hline $7 \alpha$-hydroxy & 572 & 482 & 343 & 253 & \\
$7 \beta$-hydroxy & 572 & 482 & 343 & 253 & 129 & \\
$\beta$-epoxy & 500 & 410 & 349 & 253 & 129 & \\
$\alpha$-epoxy & 500 & 485 & 410 & 349 & 253 & 129 \\
triol & 590 & 572 & 482 & 429 & 253 & 129 \\
7-keto & 498 & 455 & 386 & 359 & 269 & 129 \\
\hline
\end{tabular}

Table 5. Mass Spectrometric Data of TMS Derivatives of Campesterol Oxides

\begin{tabular}{lllllll}
\hline & M+ & \multicolumn{5}{c}{ major significant ions } \\
\hline $7 \alpha$-hydroxy & 560 & 470 & 455 & 233 & 129 & \\
$7 \beta$-hydroxy & 560 & 470 & 455 & 233 & 129 & \\
$\beta$-epoxy & 488 & 473 & 398 & 370 & 253 & \\
$\alpha$-epoxy & 488 & 473 & 398 & 380 & 253 & 129 \\
triol & 578 & 560 & 470 & 417 & 335 & 129 \\
7 -keto & 486 & 396 & 381 & 269 & 129 & \\
\hline
\end{tabular}<smiles>CC1C(C)[C@]2(C)CC[C@@H](O)CC2=C[C@@H]1O</smiles><smiles>CC1C(O)C=C2C[C@H](O)CCC2(C)C1C</smiles><smiles>CC1C[C@H]2O[C@]23C[C@H](O)CC[C@]13C</smiles>

$5,6 \alpha-$ epoxy

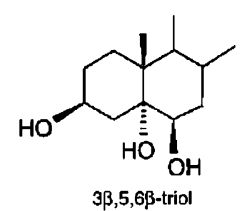

b

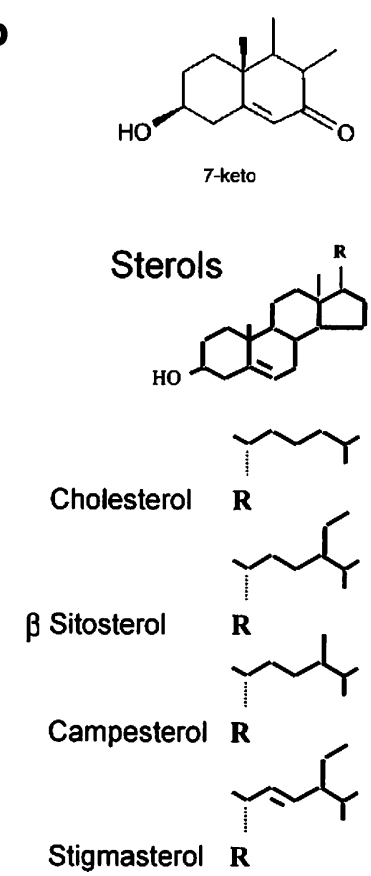

Figure 2. (a) Structure of the main sterol oxides. (b) Structure of the main sterols.

and $\beta$-sitosterol was consequently confirmed. Chemical structures of final synthesized compounds are given in Figure 2.

Analysis of Spreads. After setting up a method for the determination of POPs, a study about their presence in a commercial spread enriched with phytosterols and the corresponding nonenriched product was performed.
Table 6. Amount of Phytosterol $\left(\mathrm{g} / 100 \mathrm{~g}\right.$ Sample) in the Spreads ${ }^{a}$

\begin{tabular}{lcc}
\hline & nonenriched & enriched \\
\hline brassicasterol & $0.02(0.01)$ & $0.20(0.03)$ \\
campesterol & $0.08(0.01)$ & $1.70(0.01)$ \\
stigmasterol & $0.04(0.01)$ & $1.12(0.03)$ \\
$\beta$-sitosterol & $0.19(0.02)$ & $3.00(0.02)$ \\
total & $0.33(0.02)$ & $6.02(0.03)$
\end{tabular}

${ }^{a}$ Values are given as means and standard deviations between parentheses.

Table 6 shows that the total phytosterols content of the enriched and nonenriched spread was 6.02 and $0.33 \mathrm{~g} / 100 \mathrm{~g}$ sample, respectively. The percentages of the main phytosterols in the enriched and the nonenriched products were 49.83 and $57.58 \%$ for $\beta$-sitosterol, 28.24 and $24.24 \%$ for campesterol, 18.60 and $12.12 \%$ for stigmasterol, and 3.32 and $6.06 \%$ for brassicasterol; the latter might derive from rapeseed oil added as vegetable oil in the product formulation. The sterol analysis also showed a small amount of cholesterol in both spreads (30 and $10 \mathrm{mg} / 100 \mathrm{~g}$ sample in enriched and nonenriched samples, respectively), which might be due to the use of milk derivatives (buttermilk) in the product formulation.

Table 7 reports the amount of phytosterol oxides found in the two types of spreads; it must be noticed that brassicasterol oxides were not analyzed. The main POPs found in the spreads were 7-keto derivatives of all phytosterols analyzed, followed by $7 \beta$-hydroxysitosterol. This oxidative behavior agrees with what has already been observed in previous studies of cholesterol oxidation (36), where the 7-keto derivative was pointed out as a tracer of the oxidation process.

The total amount of POPs found in the enriched and the nonenriched spreads was $46.50 \mathrm{mg} / \mathrm{kg}$ of sample and $13.31 \mathrm{mg} /$ $\mathrm{kg}$ of sample, respectively, which resulted in a phytosterol oxidation rate of 0.07 and $0.41 \%$ for the enriched and the nonenriched products. These results agree with those of Grandgirard et al. (33), who found $68 \mathrm{mg} / \mathrm{kg}$ of sample of oxyphytosterols and a $0.08 \%$ phytosterol oxidation rate in a commercial spread enriched with phytosterol esters. It must be noticed that the fat content of the enriched spread $(44.1 \%)$ was much lower than that of the nonenriched one $(62.7 \%)$, so the total amount of POPs expressed on lipid basis was 105.7 and $21.2 \mu \mathrm{g} / \mathrm{g}$ lipid for the enriched and nonenriched spreads, respectively. The main source of POPs in the enriched products seems to be the added phytosterols (about $80 \%$ of total POPs), rather than those already present in the vegetable oils (about $20 \%$ of total POPs) used as ingredients. The latter is true from the point of view of the absolute POPs amount, but because the phytosterol oxidation rate of the enriched spread is much lower than that of the nonenriched one, it seems that POPs mainly derive from oils used as raw materials, rather than from the added sterols and the spread production process. Although both spreads were manufactured by the same producer and presented a similar total fatty acid unsaturation pattern (described in the label), the authors cannot ensure that the same raw materials were utilized for their production; vegetable oils with different quality standards could have actually influenced the trend of phytosterol oxidation and given rise to such a difference on POPs content. It must be also considered that POPs can exhibit different stability depending on the POPs chemical structure and the type of refining process applied to the oils used as raw materials (37). Considering all of these aspects, more research must be performed to elucidate the real source of POPs in this type of food product.

Grandgirard et al. (33) stated that POPs found in a commercial spread enriched in phytosterol esters are probably originated 
Table 7. Amount of Phytosterol Oxides (mg/kg in Sample) and Percentage of Phytosterols Oxidation Found in the Spreads ${ }^{a}$

\begin{tabular}{|c|c|c|c|c|c|c|c|c|}
\hline & \multicolumn{2}{|c|}{ campesterol } & \multicolumn{2}{|c|}{ stigma sterol } & \multicolumn{2}{|c|}{$\beta$-sitosterol } & \multicolumn{2}{|c|}{ total } \\
\hline & nonenriched & enriched & nonenriched & enriched & nonenriched & enriched & nonenriched & enriched \\
\hline $\begin{array}{l}7 \alpha \text {-hydroxy } \\
7 \beta \text {-hydroxy } \\
\beta \text {-epoxy } \\
\alpha \text {-epoxy } \\
\text { triol } \\
7 \text {-keto } \\
\text { total oxides } \\
\text { POPs/phytosterol (\%) }\end{array}$ & $\begin{array}{l}<L O Q \\
<L O Q \\
<L O Q \\
<L O Q \\
<L O Q \\
1.08(0.10) \\
1.08(0.10) \\
0.15\end{array}$ & $\begin{array}{l}1.36(0.20) \\
<L O Q \\
<L O Q \\
<L O Q \\
<L O Q \\
5.76(0.49) \\
8.61(0.52) \\
0.05\end{array}$ & $\begin{array}{l}<L O Q \\
<L O Q \\
<L O Q \\
1.49(0.04) \\
<L O Q \\
1.14(0.03) \\
2.61(0.03) \\
0.67\end{array}$ & $\begin{array}{l}1.54(0.38) \\
<L O Q \\
<L O Q \\
2.13(0.42) \\
<L O Q \\
4.22(0.38) \\
7.89(0.72) \\
0.07\end{array}$ & $\begin{array}{l}<L O Q \\
3.67(0.15) \\
<L O Q \\
<L O Q \\
<L O Q \\
5.93(0.23) \\
9.60(0.20) \\
0.49\end{array}$ & $\begin{array}{l}<L O Q \\
9.68(1.53) \\
<L O Q \\
5.3(0.52) \\
<L O Q \\
14.96(1.22) \\
30.00(2.55) \\
0.10\end{array}$ & $\begin{array}{l}<L O Q \\
3.67(0.15) \\
<L O Q \\
1.49(0.04) \\
<L O Q \\
8.15(0.15) \\
13.31(0.17) \\
0.41\end{array}$ & $\begin{array}{l}2.90(0.35) \\
9.68(1.53) \\
<L O Q \\
8.97(0.79) \\
<L O Q \\
24.94(1.83) \\
46.5(2.83) \\
0.07\end{array}$ \\
\hline
\end{tabular}

a Values are given as means and standard deviations between parentheses. LOQ (0.25 mg/kg sample).

from the oils used as raw materials, rather than from the technological process. Some studies performed on different vegetable oils confirm this hypothesis, reporting the presence of significant amounts of POPs. Dutta (38) detected $41 \mathrm{mg} / \mathrm{kg}$ of sample, $39.9 \mathrm{mg} / \mathrm{kg}$ of sample, and $46.7 \mathrm{mg} / \mathrm{kg}$ of sample of POPs in a blend of hydrogenated rapeseed/palm oil, sunflower oil, and high oleic sunflower oil. Bortolomeazzi et al. (37) found a POPs content from 4.5 to $67.5 \mathrm{mg} / \mathrm{kg}$ of sample and 4.1 to $60.1 \mathrm{mg} / \mathrm{kg}$ of sample in sunflower and maize crude oils, respectively. However, those authors did not find detectable amounts of oxyphytosterols in palm and coconut crude oils and they reported that during the refining process, some POPs underwent considerable decomposition. On the contrary, Lambelet et al. (39) found that POPs of low erucic and rapeseed oil did not change during the deodorization step, detecting 70.1 $\mathrm{mg} / \mathrm{kg}$ of sample of POPs in semirefined low erucic rapeseed oil.

Regarding the oxidative stability of the spreads, some other aspects should be considered, such as the degree of unsaturation of the lipid fraction and the occurrence and type of antioxidants. Osada et al. (40) suggested that the presence of unsaturated fatty acids can somehow favor sterol oxidation. The nutritional label of the spreads claims a PUFA content that accounts for $50 \%$ of the total fatty acids content. The oxidation rate of phytosterols could have also been affected by vitamin E $(66 \mathrm{mg} / 100 \mathrm{~g}$ sample) and vitamin A, which were listed as product ingredients. Comparing the effectiveness of different antioxidants (BHT, $\alpha$-tocopherol, rosemary extract, and green tea extract) on stigmasterol oxidation of sunflower oil during incubation at 60 ${ }^{\circ} \mathrm{C}$, Rudzinska et al. (41) observed that under the analytical conditions used, $\alpha$-tocopherol was the most efficient antioxidant. Those authors also found that the content of stigmastentriol increased the most when $\alpha$-tocopherol was added as an antioxidant. No triol derivatives were detected in the spreads analyzed in the present study though.

In conclusion, it can be stated that the analyzed nonenriched spread had $13.31 \mathrm{mg} / \mathrm{kg}$ of sample of POPs, which indicates that the potential oxidation of phytosterols is controlled, to a certain extent, by the presence of antioxidants and proper storage conditions. The phytosterol-enriched product displayed a total POPs content equal to $46.5 \mathrm{mg} / \mathrm{kg}$ of sample, which could come from the oils used as raw material, from the added phytosterols esters and/or produced during the technological or storage process. The low oxidation rate of the enriched spread suggests, however, that the addition of phytosterols esters is not the main source of POPs. This study is a preliminary application of an analytical method for the determination of POPs in food, which could also be utilized for monitoring other types of phytosterolenriched products.

\section{ACKNOWLEDGMENT}

We thank Mara Mandrioli and Stefano Savioli, University of Bologna, for their technical support and assistance during sample analysis.

\section{LITERATURE CITED}

(1) Ling, W. H.; Jones, P. J. H. Enhanced efficacy of sitostanolcontaining versus sitostanol-free phytosterol mixtures in altering of lipoprotein cholesterol levels and synthesis in rats. Atherosclerosis 1995, 118, 319-331.

(2) Weststrate, J. A.; Meijer, G. W. Plant sterol-enriched margarines and reduction of plasma total and LDL-cholesterol concentrations in normocholesterolemic and mildly hypercholesterolemic subjects. Eur. J. Clin. Nutr. 1998, 53, 319-327.

(3) 2004/4289: Commission Decision of 12 November 2004 authorising the placing on the market of milk based beverages with added phytosterols/phytostanols as novel foods or novel food ingredients under Regulation (EC) No 258/97 of the European Parliament and of the Council (notified under document number C2004 4289). Off. J. Eur. Union 2004, 366, 14-16.

(4) 2004/333/EC: Commission Decision of 31 March 2004 authorising the placing on the market of yellow fat spreads, salad dressings, milk type products, fermented milk type products, soya drinks and cheese type products with added phytosterols/ phytostanols as novel foods or novel food ingredients under Regulation (EC) No 258/97 of the European Parliament and of the Council (notified under document number C2004 1243). Off. J. Eur. Union 2004, 105, 40-42.

(5) 2004/334/EC: Commission Decision of 31 March 2004 authorising the placing on the market of yellow fat spreads, milk type products, yoghurt type products, and spicy sauces with added phytosterols/phytostanols as novel foods or novel food ingredients under Regulation (EC) No 258/97 of the European Parliament and of the Council (notified under document number $\mathrm{C} 2004$ 1244). Off. J. Eur. Union 2004, 105, 43-45.

(6) 2004/336/EC: Commission Decision of 31 March 2004 authorising the placing on the market of yellow fat spreads, milk based fruit drinks, yoghurt type products and cheese type products with added phytosterols/phytostanols as novel foods or novel food ingredients under Regulation (EC) No 258/97 of the European Parliament and of the Council (notified under document number C2004 1246). Off. J. Eur. Union 2004, 105, 49-51.

(7) 2000/500/EC: Commission Decision of 24 July 2000 on authorising the placing on the market of 'yellow fat spreads with added phytosterol esters' as a novel food or novel food ingredient under Regulation (EC) No 258/97 of the European Parliament and of the Council (notified under document number C2000 2121). Off. J. Eur. Union 2000, 200, 59-60.

(8) Bösinger, S.; Luf, W.; Brandl, E. Oxysterols: Their occurrence and biological effects. Int. Dairy J. 1993, 3, 1-33.

(9) Schroepfer, G. J., Jr. Oxysterols: Modulators of cholesterol metabolism and others processes. Physiol. Rev. 2000, 80, 361554. 
(10) Osada, K. Cholesterol oxidation products: Other biological effects. In Cholesterol and Phytosterol Oxidation Products: Analysis, Occurrence and Biological Effects; Guardiola, F., Dutta, C., Codony, R., Savage, G. P., Eds.; AOCS Press: Champaign, IL, 2002; pp 278-318.

(11) Maguire, L.; Konoplyannikov, M.; Ford, A.; Maguire, A. R.; O'Brien, N. Comparison of the cytotoxic effects of $\beta$-sitosterol oxides and a cholesterol oxide, $7 \beta$-hydroxycholesterol, in cultured mammalian cells. Br. J. Nutr. 2003, 90, 767-775.

(12) Adcox, C.; Boyd, L.; Oehrl, L.; Allen, J.; Fenner, G. Comparative effects of phytosterol oxides and cholesterol oxides in cultured macrophage-derived cell lines. J. Agric. Food Chem. 2001, 49, 2090-2095.

(13) Lea, L. J.; Hepburn, P. A.; Wolfreys, A.; Baldrick, P. Safety evaluation of phytosterol esters. Part 8 . Lack of genotoxicity and subchronic toxicity with phytosterol oxides. Food Chem. Toxicol. 2004, 42, 771-783.

(14) Hiroko, T.; Yayoi, K.; Tomoko, H.; Ikuyo, I.; Hiroyoshi, S.; Masao, S.; Ikuo, I.; Katsumi, I. Phytosterol oxidation products are absorbed in the intestinal lymphatics in rats but do not accerelate atherosclerosis in apolipoprotein E-deficient mice. $J$. Nutr. 2004, 134, 1690-1969.

(15) Dutta, P. C.; Savage, G. P. Formation and content of phytosterol oxidation products in foods. In Cholesterol and Phytosterol Oxidation Products: Analysis, Occurrence and Biological Effects; Guardiola, F., Dutta, C., Codony, R., Savage, G. P., Eds.; AOCS Press: Champaign, IL, 2002; pp 319-334.

(16) Dutta, P. C. Determination of phytosterol oxidation products in foods and biological samples. In Cholesterol and Phytosterol Oxidation Products: Analysis, Occurrence and Biological Effects; Guardiola, F., Dutta, C., Codony, R., Savage, G. P., Eds.; AOCS Press: Champaign, IL, 2002; pp 335-374.

(17) Grandgirard, A. Biological effects of phytosterol oxidation products, future research areas and concluding remarks. In Cholesterol and Phytosterol Oxidation Products: Analysis, Occurrence and Biological Effects; Guardiola, F., Dutta, C., Codony, R., Savage, G. P., Eds.; AOCS Press: Champaign, IL, 2002; pp 375-382.

(18) Lampi, A. M.; Juntunen, L.; Toivo, J.; Piironen, V. Determination of thermo-oxidation products of plant sterols. J. Chromatogr. B 2002, 777, 83-92.

(19) Johnsson, L.; Dutta, P. C. Characterization of side-chain oxidation products of sitosterol and campesterol by chromatographic and spectroscopic methods. J. Am. Oil Chem. Soc. 2003, 80, 767776.

(20) Johnsson, L.; Andersson, R.; Dutta, P. C. Side-chain autoxidation of stigmasterol and analysis of a mixture of phytosteol oxidation products by chromatographic and spectroscopic methods. J. Am. Oil Chem. Soc. 2003, 80, 777-783.

(21) Apprich, S.; Ulberth, F. Gas chromatographic properties of common cholesterol and phytosterol oxidation products. $J$. Chromatogr. A 2004, 1055, 2169-2176.

(22) Guardiola, F.; Bou, R.; Boatella, J.; Codony, R. Analysis of sterol oxidation products in foods. J. AOAC Int. 2004, 87, 441-466.

(23) Louter, A. J. Determination of plant sterol oxidation products in plant sterol enriched spreads, fat blends and plant sterol concentrates. J. AOAC Int. 2004, 87, 485-492.

(24) Dzeletovic, S.; Breuer, O.; Lund, E.; Diczfalusy, U. Determination of cholesterol oxidation products in human plasma by isotope dilution-mass spectrometry. Anal. Biochem. 1995, 225, $73-80$.

(25) Sweeley, C. C.; Bentley, R.; Makita, M.; Wells, W. W. Gasliquid chromatography of trimethylsilyl derivatives of sugars and related substances. J. Am. Oil Chem. Soc. 1963, 85, 2497-2507.
(26) Boselli, E.; Velazco, V.; Caboni, M. F.; Lercker, G. Pressurized liquid extraction of lipids for the determination of oxysterols in egg-containing food. J. Chromatogr. A 2001, 917, 239-244.

(27) Folch, J.; Lees, M.; Sloane-Stanley, G. H. A simple method for the isolation and purification of total lipids from animal tissues. J. Biol. Chem. 1957, 226, 497-509.

(28) Sander, B. D.; Addis, P. B.; Park, S. W.; Smith, D. E. Quantification of cholesterol oxidation products in a variety of foods. J. Food Prot. 1989, 52, 109-114.

(29) Guardiola, F.; Codony, R.; Rafecas, M.; Boatella, J. Comparison of three methods for the determination of oxysterols in spraydried egg. J. Chromatogr. A 1995, 705, 289-304.

(30) Chicloye, E.; Powrie, W. D.; Fennema, O. Photooxidation of cholesterol in spray-dried egg yolk upon irradiation. J. Food Sci. 1968, 33, 581-587.

(31) Daly, G. G.; Finocchiaro, E. T.; Richardson, T. Characterization of some oxidation products of $\beta$-sitosterol. J. Agric. Food Chem. 1983, 31, 46-50.

(32) Bortolomeazzi, R.; De Zan, M.; Piazzale, L.; Conte, L. S. Mass spectrometry characterization of the $5 \alpha-, 7 \alpha$-, and $7 \alpha$-hydroxy derivatives of $\beta$-sitosterol, campesterol, stigmasterol, and brassicasterol. J. Agric. Food Chem. 1999, 47, 3069-3074.

(33) Grandgirard, A.; Martine, L.; Joffre, C.; Juaneda, P.; Berdeaux, O. Gas chromatographic separation and mass spectrometric identification of mixures of oxyphytosterol and oxycholesterol derivatives. Application to a phytosterol-enriched food. $J$. Chromatogr. A 2004, 1040, 239-250.

(34) Johnsson, L.; Dutta, P. C. Separation of phytosterol products by combination of different polarity gas chromatography capillary columns. J. Chromatogr. A 2005, 1064, 213-217.

(35) Johannes, C.; Lorenz, R. L. Preparation and mass spectrometry of 14 pure and O-18(2)-labeled oxidation products from the phytosterols beta-sitosterol and stigmasterol. Anal. Biochem. 2004, 325, 107-116.

(36) Zunin, C. P.; Calcagno, C.; Evangelisti, F. Sterol oxidation in infant milk formulas and milk cereals. J. Dairy Res. 1998, 65, 591-598.

(37) Bortolomeazzi, R.; Cordano, F.; Pizzale, L.; Conte, L. S. Presence of phytosterol oxides in crude vegetable oils and their fate during refining. J. Agric. Food Chem. 2003, 51, 2394-2401.

(38) Dutta, P. C. Studies of phytosterol oxides II: Content in some vegetable oils ans in French fries prepared in these oils. J. Am. Oil Chem. Soc. 1997, 74, 659-666.

(39) Lambelet, P.; Grandgirard, A.; Gregoire, S.; Juaneda, P.; Sebedio, J. L.; Bertoli, C. Formation of modified fatty acids and oxyphytosterols during refining of low erucic acid rapeseed oil. J. Agric. Food Chem. 2003, 51, 4284-4290.

(40) Osada, K.; Kodama, T.; Yamada, K.; Sugano, M. Oxidation of cholesterol by heating. J. Agric. Food Chem. 1993, 41, 11981202.

(41) Rudzinska, M.; Korczak, J.; Gramza, A.; Wasowicz, E. Inhibition of stigmasterol oxidation by antioxidants in purified sunflower oil. J. AOAC Int. 2004, 87, 499-504.

Received for review March 10, 2005. Revised manuscript received July 21, 2005. Accepted July 31, 2005. This work was supported by Fundación-Empresa, PIUNA, and Asociación de Amigos of the University of Navarra, Spain.

JF050539M 